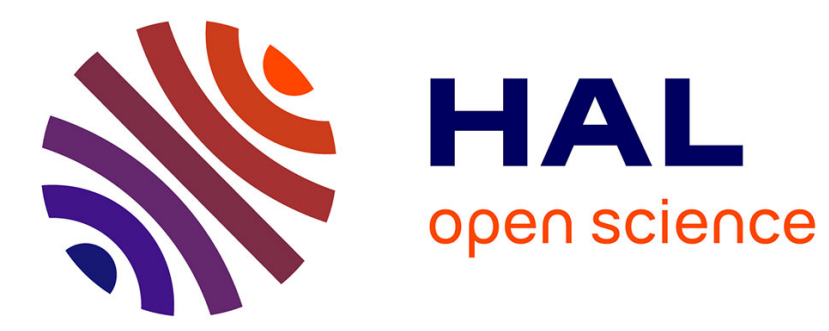

\title{
Long-term risk management for utility companies: the next challenges
}

René Aïd

\section{To cite this version:}

René Aïd. Long-term risk management for utility companies: the next challenges. 2008. hal00409030v5

\section{HAL Id: hal-00409030 \\ https://hal.science/hal-00409030v5}

Preprint submitted on 23 Sep 2009

HAL is a multi-disciplinary open access archive for the deposit and dissemination of scientific research documents, whether they are published or not. The documents may come from teaching and research institutions in France or abroad, or from public or private research centers.
L'archive ouverte pluridisciplinaire HAL, est destinée au dépôt et à la diffusion de documents scientifiques de niveau recherche, publiés ou non, émanant des établissements d'enseignement et de recherche français ou étrangers, des laboratoires publics ou privés. 


\title{
Long-term risk management for utility companies: the next challenges
}

\author{
René Aïd *
}

September 23, 2009

\begin{abstract}
Since the energy markets liberalisation at the beginning of the 1990s in Europe, electricity monopolies have gone through a profound evolution process. From an industrial organisation point of view, they lost their monopoly on their historical business, but gained the capacity to develop in any sector. Companies went public and had to upgrade their financial risk management process to international standards and implement modern risk management concepts and reporting processes (VaR, EaR...). Even though important evolutions have been accomplished, we argue here that the long-term risk management process of utility companies has not yet reached its full maturity and is still facing two main challenges. The first one concerns the time consistency of long-term and mid-term risk management processes. We show that consistencies issues are coming from the different classical financial parameters carrying information on firms' risk aversion (cost of capital and short-term risk limits) and the concepts inherited from the monopoly period, like the loss of load value, that are still involved in the utility company decision-making process. The second challenge concerns the need for quantitative models to assess their business model. With the deregulation, utilities have to address the question of their boundaries. Although intuition can provide insights on the benefits of some firm structures like vertical integration, only sound and tractable quantitative models can bring answers to the optimality of different possible firm structures.
\end{abstract}

Keywords: electricity markets; risk management; investment decision; long-term risk

JEL Classification: G11; G32. AMS Classification (2000): 90B50; 91B06; 91B28.

\section{Introduction}

Twenty years have passed since the British Conservative Party's programme in 1987 first called for liberalisation of the electricity sector [7]. Since then, the unbundling and privatisation of the British former monopolistic company CEGB in 1991 has been followed by the 96/92 European directive creating de facto a single European electricity market and has spread around the world [10]. If one looks back at the different events that punctuated these years (California crisis, Enron's fraud and fall, the mitigated success of the Pool [21], the frequent spot price spikes, the increase in fossil energy prices, some black outs in the US and in Europe...), the act of faith in the efficiency of market mechanisms that lead to the liberalisation process seems to have raised more issues, questions and problems than what was expected.

While a vast scientific literature has been written on these issues, mainly two subjects have attracted the attention of the financial and economic community: market regulation mechanisms, on the one hand, and pricing and market risk management, on the other. These two subjects drew the attention of the financial and economic community because the very technical and non-storable nature of electricity was raising new, stimulating and economically important challenges. From the regulation perspective, the main question is if

* EDF RED, 1 Avenue du Général de Gaulle, F-92141 Clamart Cedex E Finance of Energy Markets Laboratory, joint laboratory Paris Dauphine University, CREST and EDF RED, rene.aid@edf.fr 
the special electricity properties would require special market mechanisms to mitigate market power in the spot market and allow production investment in the long run [45, 23, 43, 44]. From a derivatives pricing perspective, the fact that electricity does not satisfy the main assumption of commodity price modelling (storability) opens the door to a new research area for mathematical finance [38, 17, 8, 2]. Regarding risk management in the electricity business, the literature is as huge as the preceding one. For a general introduction to risk management specificities in electricity markets one could refer to Deng and Oren's work [12], but also to Liu's survey [48] and Pereira's paper [37], amongst others [28, 29, 47, 11]. For specific problems, such as the unit commitment combined with risk management constraints, one can refer to [33, 9, 22]. Finally, for long-term price modelling, one can find a first entry in Olsina's work [35].

However, it is harder to find research work on the impact of liberalisation on former monopolies considered as competitive firms and, in particular, to find quantitative models describing what they should do. One can find in Bunn's work [7], followed by Larsen [27] and Dyner [14] a description of the changes through which monopolies have gone. As pointed out in Bunn's comments in [7], the first impact of privatisation of former monopolies was somehow to compel them to a cultural change, going from an engineer perspectives on power systems to a more competitive and commercial oriented policy. In this cultural change, methodological and modelling aspects have been left aside, far away from strategic actions of greater importance, like structural reforms to increase productivity and mergers and acquisition to reach a strategic size. It has also been said that the rather frantic period of the 1990s when acquisitions were done in many directions (network, water...) was the sign that former monopolies were learning to live freely, without the speciality principle that was the counterpart of their monopoly.

Nevertheless, the evolution from planning to strategic thinking described by Dyner et al. in [14] is not free of methodological and practical challenges. In fact, since monopolies had implemented over the years computer-based systems to support their generation management decisions, practical difficulties came first. These IT systems represented hundreds of thousands of lines of code, which were suddenly asked to take into account spot and futures prices, emission quotas, and financial risk constraints; a multitude of changes for which they were not designed. Moreover, new management concepts like Value at Risk (VaR), which was common in trading entities, spread within electricity firms and raised methodological issues when they had to be coordinated with the former economical concepts and parameters defined during the monopoly period and which are still haunting the computer-based decision-making systems.

The object of this paper is to pay special attention to this moment in the history of old monopolies becoming young listed firms and to focus on the methodological issues that still remain in the coordination of their risk management and investment decision-making process. In our opinion, it is not possible to fully appreciate the challenge faced by former monopolies without an explanation of the economic system they built over the past decades. Therefore, this paper begins with a description of the electricity monopoly economic model (section 2) to put into perspective with the present situation the way investment decisions were done and coordinated with generation management decisions. Subsequently, we recall the main changes entailed by the deregulation process (section 3), paying special attention to firms' increased financial stress factors. We then describe the adaptation responses developed by electricity firms (section 4). The final part of this paper is dedicated to the methodological challenges utilities are facing in their long-term risk management process to achieve a comprehensive view of their actions: rebuilding a time consistency of risk management and investment decisions (section 5.1) and developing quantitative models to assess their business model (section 5.2).

\section{The economic model of regulated electric monopoly}

The boundaries and objective of the electric monopolies were not a question for their board of directors; said items were determined by the government. The purpose assigned to regulated electric monopolies was to satisfy the demand at least cost and within a quality level specified by a probability of system failure per year. The fact that they had a monopoly on power was counterbalanced by the fact that it was limited to this specific business sector (speciality principle of regulated monopoly). In general, the monopoly was vertically 
integrated covering production, transportation and distribution of electricity. Generally, after WW2, they had a national basis in Europe (except in Germany, where they had a Land basis) and they were owned by the state. Since it was in the interest of the national authority that the electric monopoly reach its objective, i.e. security of supply, the former provided significant resources and legal facilities to the latter. They had complete access to information on consumption and the state of the production mix, and they were not particularly troubled by increases in input prices because they could recover financial losses to final consumers by an offsetting increase in the electricity price.

This environment was favourable to the development of a mode of governance of the electrical system based on planning, i.e. on the use of optimisation and operations research methods to develop and manage the production mix. Such a trend was reflected throughout the world in all national monopolies and France was no exception. In this country, Pierre Masse's seminal work on hydraulic investment and reservoir management [30] was followed by Marcel Boiteux's marginal cost-pricing theory [4] and its operational implementation by EDF's economic departments [18, 32, 15].

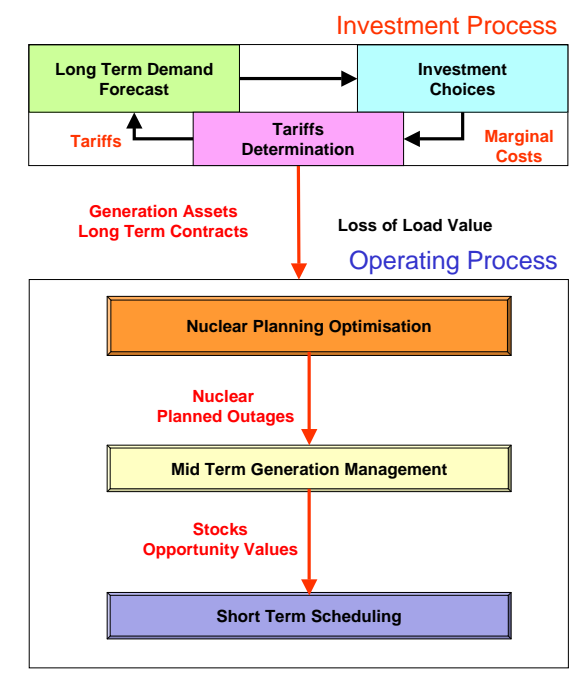

Figure 1: General outline decisions process in an electricity monopoly.

The general management scheme is summarized in Figure 1. Each of the two essential building blocks of this process (Investment and Operating Process) was based on the computation of an economic equilibrium. The first one is a long-term equilibrium between the level of investment and consumption. Its purpose was to define the optimal level of investment in each generation technology and to compute the electricity tariffs reflecting the marginal costs of electricity. The second one is a medium-term equilibrium (yearly scheduling) followed by a short-term one (daily scheduling). We will present this general scheme starting from the way time consistency was insured between the investment level and the operating level, then we will present the optimisation problem solved by the investment decision process and will finish by the way tariffs were built.

The time consistency of decisions between investment and operational management of production assets was insured through a unique valorisation $\delta$ of the loss of load probability, known as the value of loss of load. Hence, the importance of this parameter cannot be stressed enough. Two methods were generally discussed to determine its value. The first one consisted in inquiries amongst consumers asked to estimate the prejudice of being cut off (explicit method). This method had the drawback of generating many different 
values that were difficult to aggregate. The second method was based on an economic argument: it should be equivalent to society to cut the demand during a given numbers of hours per year or to build a peaking unit that would run only for this number of hours per year. Letting $I$ be the unitary investment cost in a peaking unit, $c_{f}$ be the annual fixed cost per MW of the peaking unit, $c_{p}$ be its proportional cost, $\beta=1 /(1+a)$ be the public discount factor for a discount rate of $a$, and $N$ the number of hours of allowed system failure, and considering that the investment is done at the beginning of the year without any delay, the value of the loss of load $\delta$ satisfies the relation:

$$
\sum_{t=0}^{+\infty} \beta^{t} N \delta=I+\sum_{t=0}^{+\infty} \beta^{t}\left(c_{f}+N \times c_{p}\right)
$$

which gives:

$$
\delta=c_{p}+\frac{1}{N}\left(c_{f}+(1-\beta) I\right)
$$

For instance, for $N=4$ hours of black out per year, and given standard cost of a gas peaking unit with $I \approx 300$ Euro $/ \mathrm{kW}, c_{f} \approx 8$ Euro/kW, $c_{p} \approx 150$ Euro/MWh, and a discount rate of $8 \%$, one gets a loss of value of roughly $\delta \approx 2000$ Euro/MWh, which should remind the spot prices order of magnitude to the reader.

Due to the complexity of the interaction between production and demand, the heterogeneity of production assets, the variety of their technical constraints, uncertainties about the future (demand, inflows, outages, fossils energy prices), it was not possible to tackle the optimal investment decision problem by brute force. To give a mathematical overview of the successive models involved in the management process of Figure 1, we follow the presentation of EDF's Economic department $[32,15]$ and leave aside the optimal maintenance scheduling of nuclear plants. The investment problem (Figure 1 light blue box) was decomposed in a global one and a local one. The objective of the global problem was to determine the level of investment of each production technology (coal, fuel, gas, nuclear). Technologies were differentiated only with their different cost structure (fixed and fuel costs) leaving aside their different dynamical constraints. If we define,

- $X_{t}$ : the vector of installed capacity at the beginning of year $t$, its components represent the installed capacity for each available technology,

- $U_{t}$ : the vector of investment added or withdrawn at the beginning of year $t$;

- $J_{t}$ : the vector of unitary discounted investment cost $i$ at the beginning of year $t$,

- $G_{t}\left(X_{t}+U_{t}\right)$ : the expected management cost of capacity $X_{t}+U_{t}$ during year $t$,

- $L_{t}\left(X_{t}+U_{t}\right)=\delta . l_{t}$ : the loss of load cost for the installed capacity $X_{t}+U_{t}$ during year $t$ for $l_{t}$ unserved demand.

then, the problem to solve was :

$$
\min _{U_{t}} \sum_{t=0}^{T-1} \beta^{t}\left(J_{t} \cdot U_{t}+G_{t}\left(X_{t}+U_{t}\right)+L_{t}\left(X_{t}+U_{t}\right)\right)+S\left(X_{T}\right),
$$

w.r.t.

$$
X_{t+1}=X_{t}+U_{t}
$$

where $S$ is a final value fonction.

Some remarks should be made here on this problem and its solution. First, one is surprised not to see a demand constraint. This constraint is hidden in the management cost function $G_{t}$. This function is itself the result of an optimisation problem presented below (see problem (5)). It is an expectation computed on the different demand scenarios produced by the demand forecast process (Figure 1 Green Box) and 
taking into account different inflow and outage scenarios. Nevertheless, the investment problem solution is a deterministic policy; it is not adapted to future contingencies. Delays were taken into account by putting additional constraints on the problem. Finally, one can already notice that the greater the value of $\delta$ is, the more investment will be done.

We come now to the mid-term generation management problem (Figure 1 Yellow Box) producing the value of the function $G_{t}$ needed in the global investment problem (3). If we define:

- $x_{t, s}^{i}$ : the level of energy reserve $i$ at time $t$ on scenario $s$,

- $\mathbf{a}_{t, s}^{i}$ : the inflows to energy reserves $i$ at time $t$ on scenario $s$,

- $v_{t, s}^{i}$ : the energy turbined from $i$ at time $t$ on scenario $s$,

- $c_{t, s}^{j}$ : the fuel cost of thermal unit $i$ at time $t$

- $u_{t, s}^{j}$ : production of thermal unit $i$ at time $t$ on scenario $s$,

- $\mathbf{D}_{t, s}^{j}$ : demand at time $t$ on scenario $s$,

- $T_{y}$ : the number of time steps in which the year is divided.

Then one has to solve the following form:

$$
G_{0}\left(X_{0}\right)=\min _{u_{t, s}^{i}, v_{t, s}^{j}} \mathbb{E}\left[\sum_{t=0}^{T_{y}}\left(\sum_{i} c_{t}^{i} \cdot u_{t, s}^{i}+\delta \cdot l_{t, s}\right)+V\left(x_{T, s}^{1}, \ldots, x_{T, s}^{J}\right)\right],
$$

w.r.t.

$$
\begin{aligned}
x_{t+1}^{j} & =x_{t, s}^{j}-v_{t, s}^{j}+\mathbf{a}_{t, s}^{j} \\
\sum_{i} u_{t, s}^{i}+\sum_{j} v_{t, s}^{j}+l_{t, s} & =\mathbf{D}_{t, s},
\end{aligned}
$$

and the usual bound constraints on the production variables.

There has been much research work on the compared efficiencies of different numerical optimisation methods that can be used to solve this problem (Pontryagin principle, Lagrangian relaxation, stochastic dual dynamic programming...). The important point concerning our discussion here is the presence of the loss of load value within the mid-term decision-making process. The management of all the energy reserves are affected by this value in a simple way: the higher the loss of load is, the more cautious the storage management strategy is. The loss of load value acts as a risk aversion coefficient, indicating a time preference between saving now or later.

Once the global problem (3) was solved, a valuation of each specific investment project considering all its different technological constraints and specificities was performed using the marginal costs, $\lambda_{t, s}=\partial G_{0} / \partial D_{t, s}$. The project's NPV was computed using the relation:

$$
v=\sum_{t=0}^{T_{I}} \beta^{t} I_{t}+\mathbb{E}\left[\sum_{t=T_{I}+1}^{T-1} \beta^{t}\left(\lambda_{t, s} g_{t, s}-c_{t, s}\right)\right],
$$

where:

- $T_{I}$ : construction time of the project,

- $T$ : lifetime of the asset, 
- $I_{t}$ : investment costs required by the project

- $\lambda_{t, s}$ : expected marginal cost at time $t$ on scenario $s$

- $g_{t, s}$ : production at time $t$ on scenario $s$

- $c_{t, s}$ : production cost during period $t$ on scenario $s$

And investment was made in the project as soon as $v$ was positive. We will see below in section 5.1 that this criterion has been tighten by some electric companies.

The final step of a regulated electric monopoly was to elaborate the electricity prices for consumers. Marcel Boiteux's seminal work on marginal-cost pricing [4] and peak-load pricing [3,6] was made as operational as it could be by EDF's economic departments using the given information and means available at the beginning of the 1960s $[18,36]$. Tariffs construction was not a mere computation of the marginal costs expectation. The marginal costs depended on the time of the year and also on the realisation of random events (demand, inflows and outages). The purpose of a tariff grid was to find a compromise between economic efficiency and practicability. The economic efficiency refers to the need of making clients pay the right price of electricity whereas practicability refers to the trade-off between the precision of the information transmitted by prices and the cost of developing the corresponding metering tools. Furthermore, some other properties were required for a public tariff on electricity. Tariffs had to be stable over time and two clients with the same consumption should pay the same price. However, the grid tariff should be able also to make a difference between a client consuming $24 \mathrm{kWh}$ with $1 \mathrm{~kW}$ running during 24 hours and a client consuming the same amount but by running $24 \mathrm{~kW}$ during 1 hour. Intuition would dictate that the second client is 24 more responsible than the first one in the need of peaking unit. Reflecting such differences between clients in a simple tariff grid is a problem of great complexity due to the many ways clients consume power.

But, from the analysis of client behaviour, it can be shown that the ratio $H$ between the annual consumption $C$ and the subscribed power $P$ was a good indicator of client participation to peaking unit development. This ratio $H$ homogeneous to a time was defined as the Time-Of-Use of a client (TOU). It was possible to express the expected marginal costs as a function of $H$, whose shape was convex as shown in Figure 2.

A tariff was a linear approximation of this curve for a given $H$. It was specified with two numbers, a fixed premium corresponding to the value at the origin, and a proportional price given by the slope of the curve. A grid tariff was a set of lines approximating the curve. One can note that the fixed premium increased with $h$ and the proportional price decreased, reflecting that for an intensive use of electricity it was better for a client to choose a tariff with a large premium. If this practical construction had the benefit of being efficient, in the sense that clients were naturally guided to choose a tariff corresponding to their relative consumption behaviour between peak and base load, it was clear to economists that nothing in this construction would guaranty that the elaborated tariffs would ensure the financial equilibrium of the monopoly [5]. This last problem was solved by using tolling fees, computed as the percentage of tariffs increase needed to insure financial equilibrium. They were homogeneously spread on the grid tariffs.

\section{The new world}

The wave of liberalisation in the electricity and gas sector that began in Europe in the early 1990s has deeply changed the environment in which the economic management scheme described in the preceding section was developed. As noted by Dyner and Larsen [14], no factor remains which made possible the economic planning management system:

1. market prices may not lead anymore to investment and fixed costs recovery,

2. future evolutions in production mixes are now proprietary data that are part of players' strategy,

3. the demand addressed to each player depends on the strategies of competitors.

4. market regulation may now interfere with or even prevent firms' projects. 


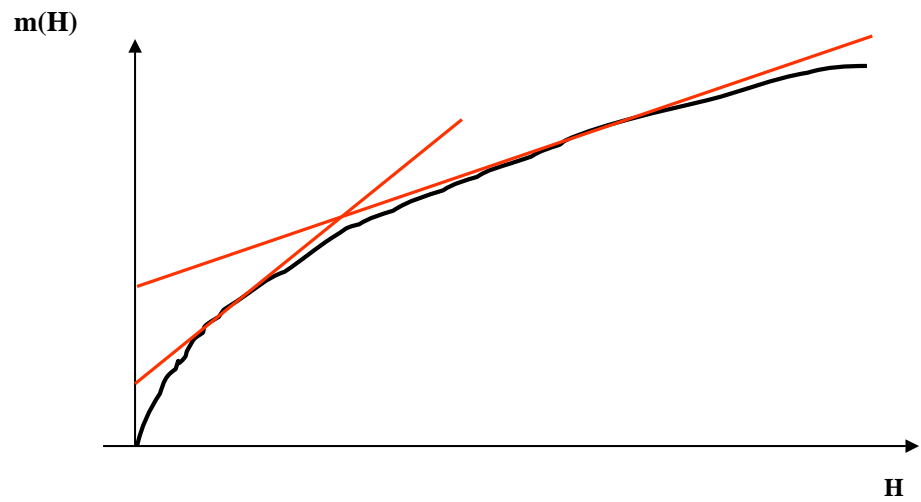

Figure 2: Expected marginal cost as a function of the TOU $H$ and its linear approximation with two tariffs.

One may suppose that the items listed above represented the changes that States wanted to subject their monopolies to: uncertainty in cost recovery and competition. But, the new world in which utilities find themselves does not only concern competition; the changes have gone far beyond this expectation. External changes can be sorted in three areas: substantial increase in energy prices volatilities, environmental regulation and financial regulation.

Deregulation of the electricity and gas sector come at a particular moment in the world's energy history: the multiplication between 2003 and 2008 by 4 of the price of a barrel (from 35 USD/bbl to $130 \mathrm{USD} / \mathrm{bbl}$ ) and by 6 of coal (from $30 \mathrm{USD} / \mathrm{t}$ to $180 \mathrm{USD} / \mathrm{t}$ ) reflecting the durable rise in demand from China and India, and followed by sudden decrease of oil price due to the financial crisis started in september 2008. But nevertheless, peak oil is no longer a subject only for experts. States and utilities consider very seriously the threat that we face from the decline in oil production.

At the same time, political and industrial communities worldwide have become aware of the anthropological effects of climate change. The Nobel Prize given in 2007 to the Intergovernmental Panel on Climate Change is the final recognition of the work they have done since 1988 on this topic. The effects of these events are numerous, some of which concern regulation mechanisms and some of which concern the corporate decision-making process. Regarding regulatory issues, the Kyoto Protocol followed in Europe by the European Directive 2003/87 led to the establishment of mechanisms to deal with externalities associated with emissions of greenhouse gases, in particular $\mathrm{CO}_{2}$. The European Trading System (ETS) put in place in Europe offers several tools for the exchange and valorisation of $\mathrm{CO}_{2}$ emissions (TEP, JI, CDM, green and white certificates). We already know that new developments are to appear in the coming years because of the learning process of both industry players and regulators. Moreover, the economic incentives provided by governments to develop decentralised and renewable electricity production can be seen as another regulatory effect, which is less analysed as a new constraint on utilities. But, these incentives are provided through subsidies and buy-back tariffs which distort production technologies competition and will lead to a substantial market share for decentralised production. Regarding the decision-making process of utilities, global warming raises substantial doubts about the usefulness of the historical statistics on temperature, hydrology 
and winds on which generation management decisions are based.

Finally, electricity and gas were not the only sectors in which a wave of liberalisation occurred during the last decades. Financial markets have also undergone liberalisation. Rules were elaborated to make it easier for investors to invest in firms in all OECD countries. In the US, this began already in 1997 with SEC Regulation S-K, which under item 305 compels corporations to disclose key information about their financial risk management system. In Europe, the same process was launched with the European Regulation 1606/2002, which made the use of IFRS standards for listed companies mandatory. These new standards (IFRS) were established to increase the clarity of the financial communication of listed firms and to give a more faithful picture of firms' balance sheets to make comparisons easier for investors. Moreover, they were established to limit the use of derivatives by companies (IAS 39) and to avoid, as far as possible, financial disasters such as Orange County and Metallgesselschaft [31]. Finally, in this financial market liberalisation process, utilities quickly learned the key role played by rating agencies (Moody's, Fitch, Standard Poor's) in their access to credit.

All those external changes came together with an internal change, which should have counterbalanced all these constraints and uncertainties: former monopolies are now free. They are no longer compelled to remain on their historical electricity business. Their boundaries are now an open question. As a matter of fact, one can see in the rush for acquisitions in Europe that followed the first years of open electricity markets a sign of this difficult exercise of freedom for utilities that were used to be limited to a particular business line. This point is of great importance for long-term risk management policy and we will come back to this crucial point in section 5.2.

\section{Firms adaptation process}

The former monopolies have gone through a profound adaptation process to tackle this new environment. We will not develop here all the cultural changes that were necessary to spur on employees used to live in a world without competition; instead we will focus on governance structure and processes adaptation to new financial risk management standards and constraints. We can sort those changes in three parts:

1. the discount factor evolution,

2. the establishment of a general financial risk control function related to markets risks,

3. the long term perspective assessment process.

The first reaction by major power utilities to market deregulation was to reconsider the discount rate they used to valuate their investment decisions. This parameter is crucial and one can even find in E.ON's 2007 annual report the breakdown of this cost of capital. All the utilities that went public significantly increased their discount rate going from a standard $8 \%$ to 10\% [7]. But, more than a simple increase that would translate a higher preference for the present of listed companies than former state-owned utilities, it reflects the change of meaning of this parameter within the financial process. It is no longer regarded as a discount rate that can be disconnected from present market conditions to reflect long-term preferences, as in public economy. It is now used as the cost of capital of the firm, meaning that every manager should have in mind the average return expected by the shareholders and the stakeholders from any new investment.

Corporations have always had to manage financial risks, such as interest rate and foreign exchange risks, and part of financial departments' duties are to protect their firm's earnings from such risks. Due to the evolution of international accounting rules and risk management standards, former utilities had to create a general risk control function. It is now possible to find in the annual reports of the main European power companies (E.ON, EDF, ENEL, RWE...) information on the general process of financial risk management (responsibility perimeter, reporting design and objectives) and values of their risk exposures for each market risk factor. In general, the risk control management structure reports either to the Chief Financial Officer or to the Chief Executive Officer directly, and its main objective is to provide a consolidated and periodically refreshed financial risk report and to secure the group's financial trajectory. The latter objective translates 
the firm's efforts to keep its financial commitments to investors. They disclose - sometimes with a wealth of detail - sensitivities values of their earnings w.r.t. interest rates, foreign exchange variations, VaR limit values, and confidence level parameters. For more details on the information disclosed by US listed companies on their risk exposure and risk measurement methodology one can refer to Emm and Lin's work [16]. Here, Table 4 gives a broad overview of these values. As one can see, the order of magnitude of VaR limits of former power monopolies are larger than an old energy firm like Total, and it is of the same order of magnitude as the VaR limits of major investment banks for commodities trading.

\begin{tabular}{|l||c||c||c|}
\hline Firm & Confidence Level & Time period (days) & Limit (MEuros) \\
\hline \hline EDF & 97,5 & 1 & 26 \\
\hline E.ON & 95 & 5 & 13 \\
\hline RWE & 95 & 1 & 40 \\
\hline ENEL & 95 & 1 & 10 \\
\hline \hline Total & 95 & 1 & 10 \\
\hline JP Morgan & 99 & 1 & 33 \\
\hline
\end{tabular}

Table 1: Power firms VaR limits in 2007 for energy markets trading activities (sources: annual reports) ; Total and J.P. Morgan (commodities and other) used as comparison purposes.

This market risk management process is designed to assess short-time market risk, i.e. to avoid the negative impact of price risk volatility on the current and maybe the following two annual fiscal years. It is not adapted to assess the financial risk involved in the firm's assets and liabilities portfolio that cannot be closed on a weekly or even annual basis. This portfolio inertia creates a long-term financial risk. Investment policy is the key process that can increase or reduce the firm's long-term financial risk exposure. For longterm risk management, the senior management of firms have restricted methodological choices, due to the overall complexity of the uncertainties described in section 3. A survey of strategic planning methods that can be of some help to assess long-term risk can be found in the work by Dyner et al. [14]. Nevertheless, intensive computer-based methods such as agent-based modelling or business simulation are less attractive to senior management than methods based on scenarios. Since the future may look like a fog due to its uncountable possible outcomes, scenarios are designed to fulfil the need of reducing this complexity to a few strategic parameters. Moreover, it has a positive benefit for the coordination of the various subsidiaries and departments of a group, using the same vision of the future and making it possible to compare investment projects. For instance, in the oil business some companies use a simple price threshold to evaluate investment in production facilities. Given all the usual financial and cost parameter values, if the production facility cannot financially survive during several years in a world where the oil price is below the threshold, the investment is not made. This rule may eliminate worthwhile investment projects, which might have been approved if one had used a more sophisticated method based on real options and stochastic processes, but it has the strategic benefit of making the decision-making process readable and robust.

\section{$5 \quad$ Next challenges for long-term risk management}

Above, we have described the background of power utilities (section 2) and the changes they have already accomplished (section 3). In this part of the paper we present what we believe are the next challenges for their long-term risk management process. In a nutshell, we would say that power utilities face two main difficulties: first, they have to rebuild the time consistency of their economic decision-making process (section 5.1), and second, they have to build pertinent quantitative models to assess the problem of bounding their business model (section 5.2). 


\subsection{Economic decision and risk management time consistency}

Although the key principles and management processes are already in place in the former monopolies, the fact that they had to move from a complete and mature economic model to new financial risk paradigms raises consistency issues. First of all, financial risk is managed through different parameters whose consistency is not obvious. The question of consistency between cost of capital and risk limits on risk indicators like Value at Risk (VaR) and Earnings at Risk (EaR) is not limited to former power utilities and is not perceived by listed companies as an issue since their utility perimeter is seen to be quite separated: short-term gross market and trading activities for $\mathrm{VaR}$ and investment project valuation for cost of capital. Nevertheless, they both tell something about firms' risk preferences and both put a constraint on the utilisation of capital, even if it is not over the same time scale. But, this consistency problem is made more complicated for power utilities as a result of the loss of the load value parameter (see section 2). This parameter gives an economic value to a physical probability constraint of system failure. In the monopoly period, it had an operational impact on generation management decisions, and hence on the annual fuel bill. But, it was an internal parameter and monopolies never had to pay the loss of load value to clients. Now, in the context of the electricity market, former monopolies placed in a context of difficult market conditions (high demand, low production availability) have to face the decision whether or not to buy the missing megawatts at a price close to the loss of load value. Since they still have national responsibilities and fear a system failure, they never take the risk of a general system failure and therefore buy the last missing megawatts at high prices, which gives rise to the characteristic spikes in electricity spot prices. Now, they pay the loss of load value to avoid cutting off clients (which is a sort a paradox). Hence, this parameter is also carrying information on the financial risk aversion of utilities companies and should be consistent with risk limits and cost of capital.

Moreover, we emphasised in section 2 that the regulated economic model of former monopolies relied on the computation of fictitious spot prices, which were short-term marginal costs. One might think that the emergence of wholesale electricity market prices would render obsolete this complex system of successive optimisation models to compute economic equilibriums and that managers in all business units would simply and directly replace in their valuation model marginal costs by spot prices. But, the wholesale price system for electricity suffers from limitations that still make it necessary, at the present time, to calculate equilibrium prices. Of course, electricity spot prices are a pertinent indicator to guide generation management on a daily basis. But, the shortness of the futures market horizon (3 years) makes these economic indicators useless to guide firms in investment decisions involving assets whose lifetime exceeds at least 30 years and sometimes reaches a century. Hence, a standard investment decision process could now be summarized as in Figure 3. In this scheme, risk is being taken into account by a constant cost of capital over time and non-differentiated by sector (aggregated cost of capital) and the prices are the results of a joint process involving both economic experts and long-term equilibrium prices computation.

The result of market price limitations is the cohabitation in utilities of two systems of production assets valuation: on an annual basis, production assets can be valuated as real options using electricity spot prices (see $[13,19,46,39])$; on a long-term basis, production assets are valuated w.r.t. equilibrium prices (long-term marginal costs).

This cohabitation raises two problems. First, the estimation of the NPV is done with a forecast that is disconnected from the realisation of real future spots prices. Second, since equilibrium prices are the result of the equilibrium between supply and demand of electricity, any new investment has a zero marginal value. Hence, if it is used to compute a NPV as described in problem (9), it will produce a null value. Hence, the coexistence of these two pricing systems still presents methodological problems of overall time consistency.

The problem raised is here does fall into the question of a global consistent risk management policy for which methodologies like Enterprise Risk Management try to provide a general setting [34, 20]. Nevertheless, this general setting is maybe too broad to give quantitative answers in the very small and precise, but in our view crucial, problem of time consistency of risk allocation and management. 


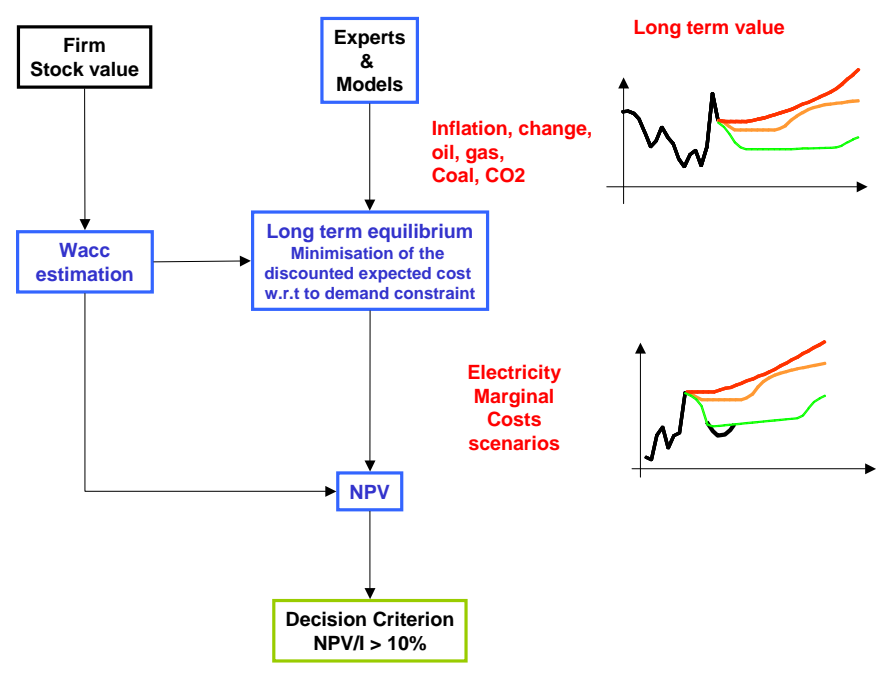

Figure 3: Outline of the process of investment decision. The cost of capital enters in the calculation of the economic equilibrium and in the NPV computation.

\subsection{Quantitative models to assess utilities business model bounds}

If one considers the changes already implemented by the former monopolies to face the new world challenges, but also the huge complexity and the tremendous increase in uncertainty, it is legitimate to wonder if there is still room for methods based on optimisation techniques or if all attempts to embrace this complexity and uncertainty are doomed to failure and one should be satisfied with the process currently used in firms. If we focus on long-term financial risks, which can take several forms (financial distress, bankruptcy or lower profitability compared to competitors), it seems fairly intuitive to consider that over the long term the structure or the company business model is a financial risk management tool. The expression "business model" covers the distribution of company assets between the production of fuel (mine, upstream gas, oil exploration), production of electricity and heat, as well as the client portfolio. The integrated business model is often invoked as a better guarantee of longevity w.r.t. financial risks. The fraudulent practices of Enron have attracted all the attention and made people forget that its business model was based solely on trading and on the belief that integrated utilities were outdated ${ }^{1}$. Moreover, Enron's collapse almost left in the shadows the less romantic but equally tragic bankruptcy of British Energy. This non-vertically integrated firm, which specialized in the production of electricity with nuclear assets, saw its revenues no longer cover its fixed costs when the bubble gas in England burst, thus leading to a collapse in wholesale market prices.

However, this benefit of vertical integration in the long term relies on sound economic intuition and would need to be enhanced by quantitative models that could explain to what level a power firm has to be integrated and on what business lines. We want to stress here the two main obstacles that make it difficult for the research for a quantitative model to provide insights on this question.

First, production assets have very differentiated technical characteristics; the temporal components, in particular, are very differentiated. It is well known that it takes 7 years to build a nuclear power plant (in the best of cases) whose lifetime is expected to be 40 or 60 years and will be decommissioned in 20 years;

\footnotetext{
1" Integrated Energy Companies Becoming Archaic", said M. Skilling, Enron Ceo, as quoted by Jeff Shares in Pipeline \& Gas Journal, January 2001
} 
even if other production assets have shorter lifetimes, they give rise to a commitment of at least 40 years for a coal plant. The same properties arise on customer contracts: some have a maturity of 15 years with complex indexation and can be regarded as investments, others are contracts whose maturity corresponds to futures market maturity and, finally, the residential costumers portfolio is subject to a permanent churn (client portfolio turnover). Moreover, all those assets produce earnings w.r.t. different prices (spot prices, futures prices, retail prices or regulated prices) that also have very different dynamics (see Figure 4)

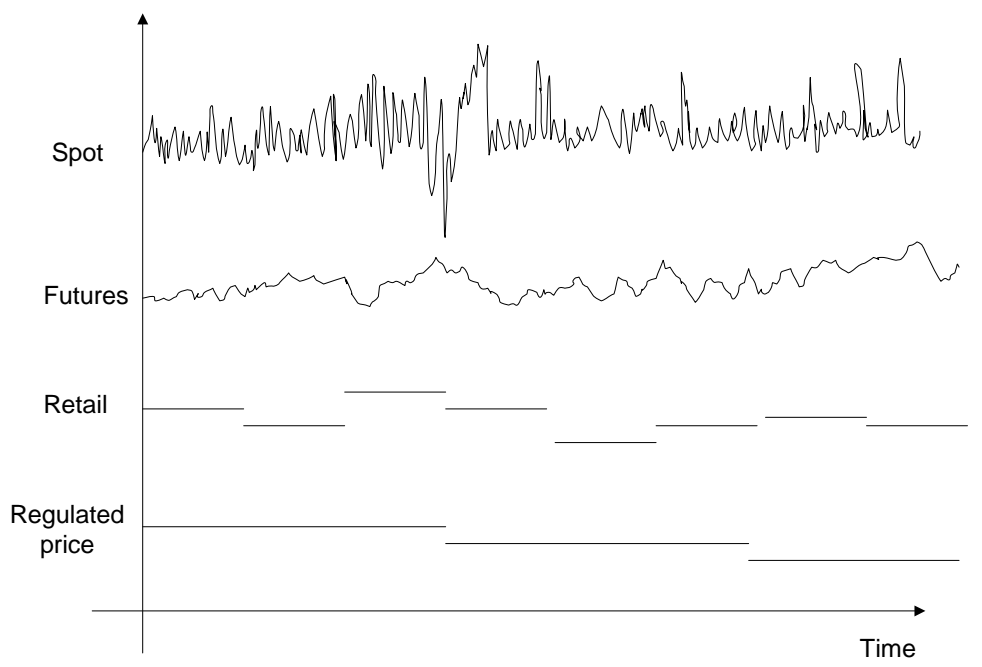

Figure 4: The dynamics of different electricity prices excluding trend: spot (high volatility of $200 \%$ and peaks), term (volatility of about 20\%), retail market indexed to the futures price (the price changes every year) Tariffs: the price varies very slowly.

Second, it is not an easy task to find a tractable quantitative criterion reflecting the idea that the company would find a good compromise between performance and risk. The choice of a mean-variance criterion is often chosen for its tractability at the expense of its realism. Presently, the scientific literature already has several works on the application of Markowitz's optimum portfolio theory to energy mix [42, 24, 25], as well as studies on the relationship between the corporate structure of the electricity sector and their stock market valuation [40] or economies of scale obtained by vertical integration from an econometric point of view [26] or from a partial equilibrium point of view [1].

However, these works, which give a first insight into the benefit of integration or generation mix diversification, could be developed in two directions. On the one hand, the time dimension is very simplified and generally limited to two or three time steps because of the complexity involved with multiple time steps. This limitation makes it difficult to draw conclusions about the sustainability of portfolio choices. On the other hand, the assets space choice is often limited to a few assets (assets production by fossil energy, in general) while the range of assets for the company is a much wider choice of energy (centralised, decentralized), long-term contracts, contracts for the short-term, the wholesale market, the retail market, long-term supply contracts or acquisition of mines, and can even include shares of companies of other companies.

We see continuous time modelling as a possible alternative to deal with the computation involved in writing directly an investment model in discrete time. Continuous time models could establish a link between company stock value dynamics and the choice of portfolio assets and tell us something about the long-term effects of a given portfolio choice. The theory developed by J.-C. Rochet on the optimal dividend policy [41] could be extended to the case where the trend and the volatility of the company's assets are controlled 


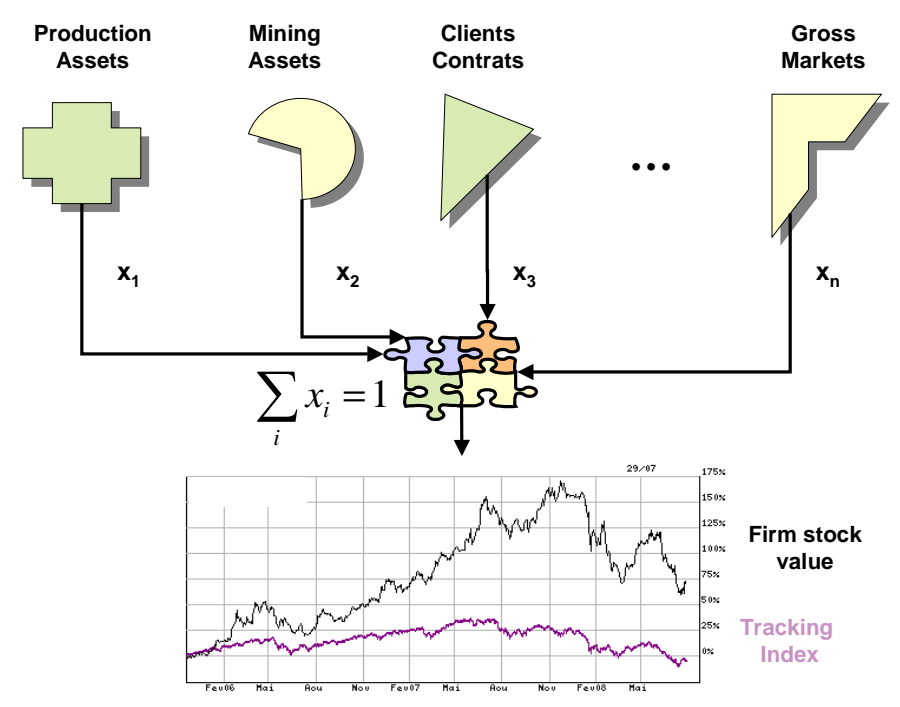

Figure 5: Building of a portfolio of physical assets and financial heterogeneous to build a risk profile tracking a benchmark.

(Figure 5). In this setting, the firm portfolio would be connected to its risk profile and would then, allow the analysis of different performance criterion, like index tracking or expected life time maximisation.

\section{Conclusion}

Starting with a description of the economic model of the former monopolies and presenting their adaptation process to modern financial risk management concepts and processes, this paper's intention was to show that there are still challenges for their long-term risk management methodology to achieve the same level of time consistency reached during the monopoly period. Moreover, we show that their business model is now an open question needing quantitative models to provide insights regarding their optimal boundaries. We hope that this general paper will raise interest about this research area for new models in the community of mathematical finance and economists.

\section{References}

[1] R. Aïd, G. Chemla, A. Porchet, and N. Touzi, Vertical integration and risk management in competitive markets of non-storable goods., Tech. Report 2, FiME Lab, 2007.

[2] F. E. Benth, J. S. Benth, and S. Koekebakker, Stochastic modeling of electricity and related markets, World Scientific Publishing Company, 2008.

[3] M. Boiteux, La tarification des demandes en pointe : application de la théorie de la vente au coût marginal, Revue Générale de l'Electricité 58 (1949), no. 3, 321-340.

[4] _ La vente au cô̂t marginal, Revue Française de l'Energie 78 (1956), 113-117. 
[5] _ Sur la gestion des monopoles publics astreints à l'équilibre budgétaire, Econometrica 24 (1956), no. $1,22-40$.

[6] _ Peak-load pricing, The Journal of Business 33 (1960), no. 2, 157-179.

[7] D.W. Bunn, Evaluating the effects of privatisation of electricity, Journal of the Operational Research Society 45 (1994), 67-375.

[8] M. Burger, B. Graeber, and G. Schindlmayr, Managing energy risk: An integrated view on power and other energy markets, Wiley, 2008.

[9] A. J. Conejo, F. J. Nogales, J. M. Arroyo, and R.l García-Bertrand, Risk-constrained self-scheduling of a thermal power producer, IEEE Trans. on Power Systems 19 (2004), no. 3, 1569-1574.

[10] E. D. Cross, Electric utility regulation in the european union, Wiley, London, 1996.

[11] R. Dahlgren, Chen-Ching Liu, and J. Lawarree, Risk assessment in energy trading, Power Systems, IEEE Transactions on 18 (2003), no. 2, 503-511.

[12] S. J. Deng and S. S. Oren, Electricity derivatives and risk management, Energy 31 (2006), 940-953.

[13] A. Dixit and R. S. Pindyck, Investment under uncertainty, Princeton University Press, 1994.

[14] I. Dyner and E. E. Larsen, From planning to strategy in the electricity industry, Energy Policy 29 (2001), $1145-1154$.

[15] Etudes Economiques Générales, Les principes de la tarification d'Electricité de France, Electricité de France, 1987.

[16] E. E. Emm and C.-M. Lin, Choices and best practice in corporate risk management disclosure, Journal of Applied Corporate Finance 19 (2007), no. 4, 82-93.

[17] A. Eydeland and K. Wolyniec, Energy and power risk management: New developments in modeling, pricing and hedging, Wiley, 2002.

[18] M. Francony, Theory and practice of marginal cost pricing: the experience of Electricité de France, Annals of Public and Cooperative Economics 50 (1979), no. 3, 9-36.

[19] D. Gardner and Y. Zhuang., Valuation of power generation assets: A real options approach, Algo Research Quarterly 3 (2000), no. 3, 9-20.

[20] S. Gates, Incorporating strategic risk into enterprise risk management: A survey of current corporate practice, Journal of Applied Corporate Finance 18 (2006), no. 4, 81-90.

[21] R. Green, Failing electricity markets: should we shoot the pools?, Utilities Policy 11 (2003), 155-167.

[22] L. Hongling, J. Chuanwen, and Z. Yan, A review on risk-constrained hydropower scheduling in deregulated power market, Renewable and Sustainable Energy Reviews 12 (2008), 14651475.

[23] S. Hunt, Making competition work in electricity, Wiley, 2002.

[24] J.C. Jansen, L.W.M. Beurskens, and X. van Tilburg, Application of portfolio analysis to the Dutch generating mix - Reference case and two renewables cases: year 2030 - SE and GE scenario, Tech. Report ECN-C-05-100, Energy Research Center of the Netherlands, 2005.

[25] B. Krey and P. Zweifel, Efficient electricity portfolios for switzerland and the united states., Tech. Report SOI Working Paper No. 0602., University of Zurich,, 2006. 
[26] J. E. Kwoka, Vertical economies in electric power: evidence on integration and its alternatives, Int. J. Ind. Organ. 20 (2002), 653-671.

[27] E.R. Larsen and D.W. Bunn, Deregulation in electricity: understanding strategic and regulatory risk, Journal of the Operational Research Society 50 (1999), no. 4, 337-344.

[28] M. Liu and . F. Wu, Portfolio optimization in electricity markets, Electric Power Systems Research $\mathbf{7 7}$ (2007), 1000-1009.

[29] M. Liu and F. F. Wu, Risk management in a competitive electricity market, Electrical Power and Energy Systems 29 (2007), 690-697.

[30] P. Massé, Les investissements électriques, Revue de Statistiques Appliquées 1 (1953), no. 3-4, 119-129.

[31] M. H. Miller, The social costs of some recent derivatives disasters, Pacific-bassin Financial Journal 4 (1996), 113-127.

[32] B. Montfort and P. Lederer, Régulation du système offre-demande d'électricité et choix des investissements de production à Electricité de France, Electrical Power and Energy Systems 8 (1986), no. 2.

[33] E. Ni, P. B. Luh, and S. Rourke, Optimal integrated generation bidding and scheduling with risk management under a deregulated power market, IEEE Trans. on Power Systems 19 (2004), no. 1.

[34] B. W. Nocco and R. M. Stulz, Enterprise risk management: Theory and practice, Journal of Applied Corporate Finance 18 (2006), no. 4, 8-20.

[35] F. Olsina, F. Garces, and H.-J. Haubrich, Modelling long-term dynamics of electricity markets, Energy Policy (2005).

[36] P. Penz, Plannification et tarification : calcul théorique et pratique des coûts marginaux de production à EDF, Annals of Public and Cooperative Economics 50 (1979), no. 3, 81-110.

[37] M.V.F. Pereira, M.F. McCoy, and H.M. Merrill, Managing risk in the new power business, IEEE Computer Applications in Power 13 (2000), no. 2, 18-24.

[38] D. Pilipovic, Energy risk: Valuing and managing energy derivatives, McGraw-Hill, 1997.

[39] A. Porchet, N. Touzi, and X. Warin, Valuation of power plants by utility indifference and numerical computation, Mathematical Methods for Operations Research (2008).

[40] C. Pozzi and P. Vassilopoulos, The impact of vertical and horizontal integration on the value of energy firms, j. h. keppler, r. bourdonnais et j. girod ed., Palgrave Macmilan, 2007.

[41] J.-C. Rochet and S. Villeneuve, Corporate portofolio management, Annals of Finance 1 (2005), 225-243.

[42] F. A. Roques, D. M. Newbery, and W. J. Nuttall, Fuel mix diversification incentives in liberalized electricity markets: A meanvariance portfolio theory approach, Energy Economics 30 (2008), 18311849.

[43] G. Rothwell and T. Gómez, Electricity economics: Regulation and deregulation, Wiley-IEEE Press, 2003.

[44] F. P. Sioshansi, Competitive electricity markets: Design, implementation, performance, Elsevier Global Energy Policy and Economics Series, Elsevier, 08.

[45] S. Stoft, Power system economics: Designing markets for electricity, Wiley-IEEE Press, 2002.

[46] C. Tseng and G. Barz, Short-term generation asset valuation, Operations Research 50 (2002), no. 2, $297-310$. 
[47] I. Vehviläinen and J.i Keppo, Managing electricity market price risk, European Journal of Operational Research 145 (2003), no. 1, 136-147.

[48] M. Liu Wu and F.F. Yixin Ni, A survey on risk management in electricity markets, Proceeding s of the Power Engineering Society General Meeting (IEEE, ed.), Power Engineering Society General Meeting, 2006. 